\title{
A validation study of public health knowledge, skills, social responsibility and applied learning
}

\author{
Dana Vackova, Coco K. Chen, Juliana N.M. Lui, Janice M. Johnston
}

School of Public Health, LKS Faculty of Medicine, The University of Hong Kong, Hong Kong

Correspondence: Dana Vackova, Patrick Manson Building,7 Sassoon Road, Pokfulam, Hong Kong. E-mail: vackova@hku.hk

Accepted: June 09, 2018

\begin{abstract}
Objectives: To design and validate a questionnaire to measure medical students' Public Health (PH) knowledge, skills, social responsibility and applied learning as indicated in the four domains recommended by the Association of Schools \& Programmes of Public Health (ASPPH).

Methods: A cross-sectional study was conducted to develop an evaluation tool for $\mathrm{PH}$ undergraduate education through item generation, reduction, refinement and validation. The 74 preliminary items derived from the existing literature were reduced to 55 items based on expert panel review which included those with expertise in $\mathrm{PH}$, psychometrics and medical education, as well as medical students. Psychometric properties of the preliminary questionnaire were assessed as follows: frequency of endorsement for item variance; principal component analysis (PCA) with varimax rotation for item reduction and factor estimation; Cronbach's Alpha, item-total correlation and test-retest validity for internal consistency and reliability.
\end{abstract}

Results: PCA yielded five factors: PH Learning Experience (6 items); PH Risk Assessment and Communication (5 items); Future Use of Evidence in Practice (6 items); Recognition of PH as a Scientific Discipline (4 items); and PH Skills Development (3 items), explaining 72.05\% variance. Internal consistency and reliability tests were satisfactory (Cronbach's Alpha ranged from 0.87 to 0.90 ; item-total correlation $>0.59$ ). Lower paired test-retest correlations reflected instability in a social science environment.

Conclusions: An evaluation tool for community-centred $\mathrm{PH}$ education has been developed and validated. The tool measures PH knowledge, skills, social responsibilities and applied learning as recommended by the internationally recognised Association of Schools \& Programmes of Public Health (ASPPH).

Keywords: Public health, questionnaire development, validity and reliability, undergraduate medical education, ASPPH undergraduate leaning outcomes model

\section{Introduction}

Multidisciplinary Public Health (PH) represents an academic and clinical discipline that focuses on disease prevention and human health promotion through organised efforts and informed choices by individuals, communities and society as a whole. While there is broad consensus about the importance of $\mathrm{PH}$ education, medical curricula vary amongst countries and faculties in the depth and breadth of $\mathrm{PH}$ teaching and learning through differences in pedagogical approaches, core competencies, and levels of integration of undergraduate $\mathrm{PH}$ in core medical curricula. ${ }^{1-6}$ Some medical educators and health care professionals comment that undergraduate medical students are not readily equipped with skills to analyse or appraise $\mathrm{PH}$ issues as they focus primarily on case diagnosis and treatment, while others support global policy initiatives to equip fresh medical graduates with both clinical and $\mathrm{PH}$

competences. ${ }^{7,3,8,9}$

Despite the above debates, it is in unified agreement that the content of undergraduate $\mathrm{PH}$ programmes should address the local community needs, lifestyle and environment, risk communication and disease trends, and policies and recommendations. ${ }^{10-13}$ To facilitate integration of communitybased $\mathrm{PH}$ activities into different undergraduate curricula or co-curricular activities, the Association of Schools \& Programmes of Public Health (ASPPH) has developed an undergraduate learning outcomes model comprising four main domains, namely, 1) knowledge of human cultures and the physical and natural world as it relates to individual an population health, 2) intellectual and practical skills, 3) personal and social responsibility, and 4) integrative and applied learning. ${ }^{13}$ These domains are consistent with the increased 
need for community-centred pedagogy for medical education to encourage students in addressing community needs. ${ }^{13-18}$

The obvious challenges in undergraduate $\mathrm{PH}$ teaching also persist in the assessment strategies and methods applied in $\mathrm{PH}$ programme evaluation, where the universal questionnaires provided by universities do not specify in assessing students' perception on $\mathrm{PH}$ teaching and multidisciplinary PH competences development. ${ }^{6,19-21}$ In addition, previous studies showed that there is a sparse number of instruments in measuring the effectiveness of $\mathrm{PH}$ teaching and learning, in which existing ones non-comprehensively focus on a small subset of $\mathrm{PH}$ teaching and learning factors and fail to address internationally recognised $\mathrm{PH}$ domains. ${ }^{8,9,20,22,23}$ Thus, a standardized multi-dimensional questionnaire measuring the self-reported development of $\mathrm{PH}$ core competencies of local and global importance is essential amongst medical educators. Therefore, this study aims to design and validate a questionnaire to measure medical students' perceptions of undergraduate $\mathrm{PH}$ teaching and learning in all four main domains recommended by the Association of Schools \& Programmes of Public Health (ASPPH).

\section{Methods}

\section{Study design and participants}

The cross-sectional study on development and validation of a new instrument assessing student progress on gaining public health knowledge, skills, social responsibility and applied learning comprised of two stages: (1) item generation and item reduction and (2) assessment of psychometric properties. The design and development process was conducted according to the following two Association for Medical Education in Europe (AMEE) Guides: (1) Introduction to research in medical education and (2) Quantitative and qualitative methods in medical education that included qualitative and quantitative research designs and psychometric studies. ${ }^{24-26}$ The ASPPH Undergraduate Learning Outcomes Model was incorporated into the study to provide the framework for item generation and content validity using four ASPPH domains: (1) knowledge of human cultures and the physical and natural world as it relates to individual and population health, (2) intellectual and practical skills, (3) personal and social responsibility, and (4) integrative and applied learning. ${ }^{13}$ Content validation on item relevance was carried out by experts in $\mathrm{PH}$, psychometrics and curriculum development.

Years three and four undergraduate medical students who have already completed their $\mathrm{PH}$ curriculum in pre-clinical and clinical settings were invited to participate in the study by e-mail and in-person during class sessions and tutorials. Year 4 medical students ( $\mathrm{N}=20$ of 198; female 50\%, male $50 \%$ ) were randomly selected to join the validation expert team. Year 3 medical students $(\mathrm{N}=133$ of 204; female $71 \%$, male $29.0 \%$ ) completed the preliminary questionnaire.
Consequent Year 3 students completed test-retest ( $\mathrm{N}=90$ of 201 , female $46 \%$, male $54 \%$ ).

The study was carried out according to the Belmont report ethical considerations. All participants were assured that their participation is voluntary and confidential, no harm would be afflicted upon them during their study, and their refusal in participating in the study will have no impact on their course assessments or grades. ${ }^{25}$ Written consent was obtained from all participants. Each participant was assigned a unique study number, and only the research assistant had access to the master identification file. Ethical approval was obtained from the Institutional Review Board of the University of Hong Kong/Hospital Authority Hong Kong West Cluster.

\section{Setting}

The study was conducted at the Li Ka Shing Faculty of Medicine, the University of Hong Kong (HKU), where multidisciplinary PH courses are well- integrated into the Bachelor of Medicine Bachelor of Surgery (MBBS) programme. ${ }^{27}$

\section{Data collection methods}

\section{Stage 1: Item selection process and content validity}

A comprehensive literature search via Pubmed database and grey literature was completed by two researchers to identify individual items, and validated instruments and methods to evaluate $\mathrm{PH}$ teaching and learning in medical curricula (undergraduate or otherwise). The literature search identified a broad list of potential items $(\mathrm{N}=74)$ to be considered for inclusion in the questionnaire. Experts $(\mathrm{N}=8)$ held meetings in mapping the generated items to the most relevant ASPPH domain, under an assumption that knowledge and skills covered in the first two domains were considered as prerequisites for the higher level of learning process reflected in domains 3 and 4 .

\section{Procedures}

The following three-step interactive approach was adopted for item reduction: ${ }^{23}$

Firstly, $\mathrm{PH}$ experts $(\mathrm{N}=8)$ who were knowledgeable with the undergraduate curriculum were invited to rate all items by their relevance and appropriateness to public health undergraduate education and $\mathrm{PH}$ learning outcomes on a fivepoint Likert scale ( $1=$ most relevant to $5=$ not relevant). Items with an average score of 3 or above were recommended for inclusion. Secondly, MBBS Year 4 students $(\mathrm{N}=20)$ were interviewed using semi-structured questions to assess the comprehensibility, relevance and usefulness of the questionnaire items and to reduce items further. The interviews also elicited students' feedback on their undergraduate $\mathrm{PH}$ teaching and the anticipated impact of $\mathrm{PH}$ teaching and learning on their future clinical practice. Finally, experts in psychometrics, questionnaire development, and $\mathrm{PH}(\mathrm{N}=6)$ provided feedback on the questionnaire content validity, response scale selection, comprehensiveness and comprehensibility. 
The resulting preliminary questionnaire contained 55 items, where 2 were open-ended items and 53 items used a six-point Likert scale ( $1=$ strongly disagree to $6=$ strongly agree) to measurably intensify the degree of students' cognitive involvement and their commitment to either the positive or negative end of the rating scale. ${ }^{28}$

\section{Stage 2: Psychometric assessment and item refinement}

The preliminary 55-item questionnaire was distributed to Year 3 students $(\mathrm{N}=133$ of 204 , response rate $=65 \%)$ during a whole class session to conduct psychometric assessment and further refine the items.

\section{Data analysis}

Data analysis was carried out in SPSS for Windows, Version 20. Descriptive statistics including mean and variance were used to summarize the data initially. Subsequently, psychometric properties of the questionnaire were assessed, where the frequency of endorsement evaluated item variance, and the Principal Component Analysis (PCA) with varimax rotation was used for item reduction and factor estimation. Furthermore, Cronbach's Alpha, item-total correlation, and test-retest reliability were performed to evaluate the internal consistency of the questionnaire.

The frequency of endorsement was assessed by splitting the response into two categories: 'disagree' (original rating $=1,2$, and 3 ) and 'agree' (original rating $=4,5$, and 6), and then calculating the proportion of dichotomous responses. Items with very high (95\%) or very low (5\%) endorsement frequency were discarded. ${ }^{29,30}$ To examine the underlying structure of the questionnaire, the PCA with varimax rotation was used. Sampling adequacy was confirmed if KaiserMayer-Olkin (KMO) test yielded a value greater than 0.60 and significant Bartlett's test of sphericity had a p-value equal to or smaller than 0.05 ( $\mathrm{p} \leq 0.05)$. $^{31}$ Items were retained if factor loading was greater than 0.40 without cross-loading. ${ }^{32}$ The guiding criteria used to determine the number of factors was the Eigenvalue greater than 1 (Kaiser's criterion), the Scree Plot, the occurrence of more than three items per factor and total variance that would explain approximately $75 \%$ of the variance using the least number of factors. ${ }^{33}$ Additionally, Cronbach's Alpha (Alpha $>0.70$ ), item-total correlation, and test-retest reliability were used to confirm internal consistency. ${ }^{32}$ Items in the same factor that scored $<0.2$ in the inter-item correlation were discarded. ${ }^{29}$

The 24-item finalized questionnaire was distributed to the consequent Year 3 students who completed the questionnaire twice for test re-test reliability ( $\mathrm{N}=90$ of 201, response rate $=44.77 \%)$. Paired sample correlation coefficients were calculated to assess test-retest reliability.

\section{Results}

\section{Construct validity}

In the item variance test, 52 of 53 items satisfied the pre-set frequency of endorsement level of $20 \%-80 \%$. The remaining item was reworded but retained due to its conceptual importance. The KMO index was 0.85 and Bartlett's test of sphericity was significant $\left(\chi^{2}(378)=2676.35, \mathrm{p}<0.001\right)$. In total, 29 of 53 (55\%) items did not meet the factor loading criteria. To confirm the inclusion or exclusion of each of these items, factor analysis was repeated with each item being removed one by one. ${ }^{32}$

The principal component analysis yielded a 24 -item 5factor structure, confirmed by the scree plot, explaining $72.05 \%$ of the variance (Table 1). Factor 1: PH learning experience with 6 items explained $36.12 \%$ of the total variance; Factor 2: PH risk assessment and communication with 5 items explained $13.19 \%$ of the variance; Factor 3: Future use of evidence in practice with 6 items explained $9.43 \%$ of the variance; Factor 4: Recognition of $\mathrm{PH}$ as a scientific discipline with 4 items explained $7.19 \%$ of the variance; and Factor 5: PH skills development with 3 items explained $6.12 \%$ of the variance.

Table 1. Principle component analysis with communalities of each item $(\mathrm{N}=24)$

\begin{tabular}{|c|c|c|c|c|c|c|c|c|}
\hline Item & $\mathrm{F} 1$ & $\mathrm{~F} 2$ & F3 & $\mathrm{F} 4$ & F5 & Extraction & Mean & $\mathrm{SD}$ \\
\hline 1 & 0.82 & & & & & 0.77 & 4.07 & 0.84 \\
\hline 2 & 0.80 & & & & & 0.70 & 4.00 & 0.88 \\
\hline 3 & 0.76 & & & & & 0.65 & 3.82 & 1.04 \\
\hline 4 & 0.75 & & & & & 0.72 & 4.06 & 0.88 \\
\hline 5 & 0.67 & & & & & 0.61 & 4.24 & 0.88 \\
\hline 6 & 0.61 & & & & & 0.59 & 3.79 & 0.98 \\
\hline 7 & & 0.86 & & & & 0.82 & 4.34 & 0.81 \\
\hline 8 & & 0.80 & & & & 0.75 & 4.29 & 0.76 \\
\hline 9 & & 0.76 & & & & 0.71 & 4.35 & 0.85 \\
\hline 10 & & 0.74 & & & & 0.72 & 4.38 & 0.75 \\
\hline 11 & & 0.73 & & & & 0.70 & 4.36 & 0.72 \\
\hline 12 & & & 0.84 & & & 0.79 & 4.57 & 0.78 \\
\hline 13 & & & 0.83 & & & 0.73 & 4.61 & 0.69 \\
\hline 14 & & & 0.77 & & & 0.67 & 4.51 & 0.73 \\
\hline 15 & & & 0.76 & & & 0.65 & 4.34 & 0.69 \\
\hline 16 & & & 0.60 & & & 0.64 & 4.34 & 0.71 \\
\hline 17 & & & 0.59 & & & 0.60 & 3.52 & 0.97 \\
\hline 18 & & & & 0.91 & & 0.86 & 3.31 & 0.99 \\
\hline 19 & & & & 0.86 & & 0.75 & 3.36 & 1.06 \\
\hline 20 & & & & 0.82 & & 0.83 & 3.57 & 1.07 \\
\hline 21 & & & & 0.77 & & 0.69 & 4.16 & 0.71 \\
\hline 22 & & & & & 0.80 & 0.76 & 4.07 & 0.76 \\
\hline 23 & & & & & 0.79 & 0.82 & 4.09 & 0.82 \\
\hline 24 & & & & & 0.76 & 0.78 & 4.07 & 0.84 \\
\hline $\begin{array}{c}\% \\
\text { Variance }\end{array}$ & 36.12 & 13.19 & 9.43 & 7.19 & 6.12 & & & \\
\hline
\end{tabular}

Note: Factor loading less than 0.40 were removed.

\section{Measurement reliability}

Cronbach's Alpha ranged from 0.87 to 0.90 . The PH learning experience (Factor 1) consisted of 6 items (Alpha $=0.90$ ); The $\mathrm{PH}$ risk assessment and communication (Factor 2) consisted of 5 items (Alpha $=0.90)$; the Future use of evidence (Factor 3) consisted of 6 items (Alpha $=0.88)$, the Recognition of $\mathrm{PH}$ as a Scientific discipline (Factor 4) consisted of 4 items (Alpha = 0.87); and PH skill development (Factor 5) consisted of 3 items (Alpha=0.87). All factors achieved acceptable item-total correlation ranging from 0.59 to 0.85 . The final validated 24-item questionnaire was distributed for test retest reliability with paired sample correlation coefficients ranging from 0.26 to 0.61 (Table 2). 
Vackova et al. A validation study of public health

Table 2. Reliability and stability analyses performed on the final version of the questionnaire

\begin{tabular}{|c|c|c|c|c|c|}
\hline Factors & & $\begin{array}{l}\text { Number } \\
\text { of items }\end{array}$ & $\begin{array}{l}\text { Range of item-total } \\
\text { correlation }\end{array}$ & $\begin{array}{c}\text { Cronbach's alpha } \\
\text { coefficient }\end{array}$ & $\begin{array}{l}\text { Paired test-retest } \\
\text { correlation }\end{array}$ \\
\hline 1 & $\mathrm{PH}$ teaching and learning & 6 & $0.68-0.82$ & 0.90 & $0.37^{* *}$ \\
\hline 2 & PH Risk assessment a communication & 5 & $0.72-0.83$ & 0.90 & $0.61^{* *}$ \\
\hline 3 & Future use of evidence in practice & 6 & $0.65-0.79$ & 0.88 & $0.54^{* *}$ \\
\hline 4 & Perception of $\mathrm{PH}$ as a scientific discipline & 4 & $0.59-0.85$ & 0.87 & $0.50^{\star *}$ \\
\hline 5 & PH Skills Development & 3 & $0.73-0.78$ & 0.87 & $0.26^{*}$ \\
\hline
\end{tabular}

${ }^{*} \mathrm{p}<0.05 ;{ }^{* *} \mathrm{p}<0.001$

Table 3. Mapping of questionnaire items $(\mathrm{N}=24)$ to the $\mathrm{ASPPH}$ four main domains

\begin{tabular}{|c|c|c|c|c|c|}
\hline Factors & Items & $\begin{array}{l}\text { ASPPH } \\
\text { Domain } 1\end{array}$ & $\begin{array}{l}\text { ASPPH } \\
\text { Domain } 2\end{array}$ & $\begin{array}{l}\text { ASPPH } \\
\text { Domain } 3\end{array}$ & $\begin{array}{l}\text { ASPPH } \\
\text { Domain } 4\end{array}$ \\
\hline \multirow[t]{6}{*}{$\begin{array}{l}\mathrm{PH} \text { learning } \\
\text { experience }\end{array}$} & $\begin{array}{l}\text { 1. Overall, Public Health }(\mathrm{PH}) \text { teaching was effective in helping } \\
\text { me achieve the } \mathrm{PH} \text { core competencies }\end{array}$ & NA & NA & NA & NA \\
\hline & $\begin{array}{l}\text { 2. The assessment criteria were appropriate in relation to } \mathrm{PH} \\
\text { learning outcomes }\end{array}$ & NA & NA & NA & NA \\
\hline & 3. $\mathrm{PH}$ lectures inspired me to learn more about $\mathrm{PH}$ disciplines & NA & NA & NA & NA \\
\hline & 4. I was able to cope with the PH workload & NA & NA & NA & NA \\
\hline & 5. The $\mathrm{PH}$ tutors were competent in $\mathrm{PH}$ teaching & NA & NA & NA & NA \\
\hline & 6. The $\mathrm{PH}$ teaching was well organized & NA & NA & NA & NA \\
\hline \multirow[t]{5}{*}{$\begin{array}{l}\text { PH risk assessment and } \\
\text { communication }\end{array}$} & $\begin{array}{l}\text { 7. I will adopt reliable and consistent inter- and intra-professional } \\
\text { communication skills with health policy makers }\end{array}$ & & & $v$ & \\
\hline & $\begin{array}{l}\text { 8. I will adopt reliable and consistent inter- and intra-professional } \\
\text { communication skills with media }\end{array}$ & & & v & \\
\hline & 9. I will communicate health information to policymakers & & & v & \\
\hline & $\begin{array}{l}\text { 10. I am able to assess the role of lifestyle factors on } \\
\text { individual/population health }\end{array}$ & & & v & $v$ \\
\hline & $\begin{array}{l}\text { 11. I am able to assess the role of environment on population and } \\
\text { health }\end{array}$ & & & $\mathrm{v}$ & $v$ \\
\hline \multirow[t]{6}{*}{$\begin{array}{l}\text { Future use of evidence in } \\
\text { practice }\end{array}$} & $\begin{array}{l}\text { 12. I will interpret clinical research for patient care and for } \\
\text { population health }\end{array}$ & & & $\mathrm{v}$ & \\
\hline & 13. I will communicate health information to individual patients & & & $\mathrm{v}$ & \\
\hline & $\begin{array}{l}\text { 14. I will adopt reliable and consistent inter- and intra-professional } \\
\text { communication skills with other healthcare professionals }\end{array}$ & & $\mathrm{v}$ & & \\
\hline & $\begin{array}{l}\text { 15. I will communicate health information to healthcare } \\
\text { professionals }\end{array}$ & & & & $v$ \\
\hline & $\begin{array}{l}\text { 16. I will apply my critical appraisal skills to the evaluation of } \\
\text { research papers }\end{array}$ & & $\mathrm{v}$ & & \\
\hline & $\begin{array}{l}\text { 17. I will use my literature search skills to support my application } \\
\text { of evidence-based medicine }\end{array}$ & & & & $v$ \\
\hline \multirow[t]{4}{*}{$\begin{array}{l}\text { Recognition of } \mathrm{PH} \text { as a } \\
\text { scientific discipline }\end{array}$} & $\begin{array}{l}\text { 18. The application of behavioral science to medicine is common } \\
\text { sense, not a scientific discipline }\end{array}$ & $\mathrm{v}$ & & & \\
\hline & $\begin{array}{l}\text { 19. The application of } \mathrm{PH} \text { principles to clinical practice is common } \\
\text { sense, not a scientific discipline }\end{array}$ & $\mathrm{v}$ & & & \\
\hline & $\begin{array}{l}\text { 20. The application of health promotion principles to medicine is } \\
\text { common sense, not a scientific discipline }\end{array}$ & $\mathrm{v}$ & & & \\
\hline & $\begin{array}{l}\text { 21. Medicine is about people, not PH evidence-based practice } \\
\text { and statistics }\end{array}$ & v & & & \\
\hline \multirow[t]{3}{*}{$\begin{array}{l}\text { PH skills } \\
\text { development }\end{array}$} & $\begin{array}{l}\text { 22. Compared to one year ago, } \mathrm{PH} \text { teaching has enhanced my } \\
\text { skills to apply economic principles in clinical decision making }\end{array}$ & & & $v$ & $v$ \\
\hline & $\begin{array}{l}\text { 23. Compared to one year ago, } \mathrm{PH} \text { teaching has enhanced my } \\
\text { skills to promote the health of individual and public in modern } \\
\text { clinical practice }\end{array}$ & & & $\mathrm{v}$ & v \\
\hline & $\begin{array}{l}\text { 24. Compared to one year ago, } \mathrm{PH} \text { teaching has enhanced my } \\
\text { skills to address environmental } \mathrm{PH} \text { problems }\end{array}$ & & & $v$ & v \\
\hline
\end{tabular}

Notes: NA: item is not applicable for mapping; v: item was mapped to the strongest ASPPH domain assuming that knowledge and skills covered in the first two domains were prerequisites for a higher level of learning process reflected in domains 3 or 4 . Domain 1: Knowledge of human cultures and the physical and natural world as it relates to the individual and population health; Domain 2: Intellectual and practical skills; Domain 3: Personal and social responsibility; Domain 4: Integrative and applied learning ${ }^{13}$ 


\section{Mapping of the validated questionnaire items $(\mathrm{N}=24)$ to} the four ASPPH domains

All items except 6 loaded on PH learning experience (Factor 1) were mapped to the most relevant domains, under the assumption that the first two domains covering knowledge and skills were prerequisites for higher level of learning process reflected in domains 3 and 4 . Factors 2 and 5 covered mainly higher domains 3 and 4, whereas items loaded on Factor 3 and 4 were mainly aligned to the knowledge and skills (Table 3).

\section{Discussion}

As presented in this paper, a questionnaire measuring medical students' perceptions of their PH knowledge, skills, social responsibility and applied learning was developed with satisfactory validity and reliability. The underlying 4-domain ASPPH Undergraduate Learning Outcomes Model was adopted in this study as a theoretical framework for the reason that it enables undergraduate students to become more active participants in their community health through access to $\mathrm{PH}$ education integrated into different curricular and cocurricular activities. Although the ASPPH framework is not comprehensive or prescriptive, it represents the key trends in pedagogy that emphasise innovative teaching methods and problem-solving through interactive, experiential and applied learning. Additionally, the ASPPH framework includes recommendations for an educated citizenry and student's contribution to the quality of life globally and locally. ${ }^{13}$

Year 3 and 4 undergraduate medical students participated in the validation process, because they had previous experience with $\mathrm{PH}$ teaching and learning in both pre-clinical and clinical settings, therefore demonstrating better ability to comprehend knowledge, skills, social responsibilities and applied learning in $\mathrm{PH}$.

\section{Stage 1: Item selection process and content validity}

Possible biases in rating the relevance and item reduction were addressed by inviting experts from different $\mathrm{PH}$ subdisciplines and by the three-step interactive approach. Subject to their area of $\mathrm{PH}$ expertise, all experts provided their opinion on the items' appropriateness for the undergraduate level of PH education and competences. Although there was a consensus on the selected items for the preliminary questionnaire, the experts' views on the best format for the response scale varied from 5 to 7 -point Likert scale to more complex formats, for example choosing answers among different response options. Despite some research studies showing that researchers may have a preference for 5-point scale, our expert panel in psychometrics preferred an even number of ratings in the scale to eliminate the midpoint as a proxy for "no opinion" and intensify the students' commitment to the positive or negative end of scale. ${ }^{28}$

\section{Stage 2: Psychometric assessment and item refinement}

The questionnaire was found to have satisfactory internal validity and reliability. ${ }^{29,30}$ After exploratory factor analysis, the final version of the questionnaire contained 24 items loaded on five factors. The percentage of total variance of $72.05 \%$ was acceptable considering that there is usually no absolute threshold adopted for all applications in social science and even $60 \%$ total variance may be considered as satisfactory. ${ }^{32}$ The questionnaire has excellent internal consistency, as measured by Cronbach's alpha and item-total correlation. The less than the satisfactory stability of the questionnaire, as measured by paired test-retest correlation coefficient, may be contributed to potential changes in students' attitudes and perceptions due to exposure to $\mathrm{PH}$ teaching during the 2 weeks interval between test-retest. Also, only 90 out of 133 students participated in the re-test, resulting in unstable estimates.

The derived five factors in the questionnaire appeared to be independent, multidimensional, and consistent. All items, except 6 loaded on PH learning experience (Factor 1), were mapped to the four main ASPPH domains framework, i.e., $\mathrm{PH}$ knowledge, Intellectual and practical skills, Personal and social responsibilities, and Integrative and applied learning.

$\mathrm{PH}$ risk assessment and communication (Factor 2), Future use of evidence in Practice (Factor 3) and PH skills development (Factor 5) cover all four domains through items representing knowledge, inquiry and analysis, critical thinking, local and global engagement and communication, synthesis and advanced accomplishment. Factor 4 measures students' perceptions of $\mathrm{PH}$ as a scientific discipline and is especially suitable for monitoring the changes in attitudes towards $\mathrm{PH}$ in longitudinal educational studies exploring scientific foundations and skills necessary for community engagement.

\section{Limitations of the study}

First, the experts and medical students were mainly considering the local needs of undergraduate $\mathrm{PH}$ teaching and learning, which may have an impact on the content validity. Second, medical students selected by convenience sampling may not represent the views and perceptions of the entire MBBS community. Age, year of study, gender, previous engagement in community work, relevance to clinical practice and pedagogy style are among some of the factors that may affect medical students' perception towards Public Health.

Furthermore, the preliminary 55 -item questionnaire was not distributed to all MBBS students for validation, and therefore the utility of the questionnaire for evaluating the whole spectrum of the curriculum may be limited. However, by the end of Year 3, medical students have been exposed to approximately $80 \%$ of the undergraduate $\mathrm{PH}$ teaching and learning content. As perception and attitudes toward teaching and learning change over time with increasing experience 
and exposure, it would also be useful to include residents and interns in any future questionnaire validation.

In addition, Cronbach's alpha was used to measure internal reliability. However, the tau-equivalent assumptions that the items measure a single underlying construct may not be reached especially in social sciences. Thus, Cronbach's alpha may provide a below average measure for the reliability. ${ }^{34}$ Finally, the reliability and validity of the questionnaire could be tested in other countries or regions to examine the generalization of the internal structure and reliability of the questionnaire.

\section{Conclusions}

The validated questionnaire measures medical students' perception about undergraduate multidisciplinary Public Health teaching and learning. It measures perceived competencies in all four main domains recommended by the internationally recognised Association of Schools \& Programmes of Public Health, including knowledge, practical PH skills, personal and social responsibilities and integrative and applied learning. The questionnaire can be used as one of the evaluation tools in the undergraduate $\mathrm{PH}$ curriculum to evaluate changes in students' perception towards $\mathrm{PH}$ and measure $\mathrm{PH}$ competences in longitudinal studies.

\section{Acknowledgements}

Authors would like to thank Mr Alex WY Kwan for his enormous administrative support during the questionnaire development and data collection. Our thanks also belong to all $\mathrm{PH}$ experts whose valuable opinion was crucial for the questionnaire development. The HKU Teaching Development Grant financially supported this study.

\section{Conflicts of Interest}

The authors declare that they have no conflict of interest.

\section{References}

1. General Medical Council (GMC) Education Committee. 2009. Tomorrow's doctors. [Cited 20 May 2018]; Available from: https://www.gmcuk.org/Tomorrows_Doctors_1214.pdf_48905759.pdf.

2. World Health Organisation. 2005. Preparing a health care workforce for the 21st century: the challenge of chronic conditions. [Cited 20 May 2018]; Available from http://www.who.int/chp/knowledge/publications/workforce_report.pdf.

3. Berwick DM, Finkelstein JA. Preparing medical students for the continual improvement of health and health care: Abraham Flexner and the new "Public interest". Acad Med. 2010;85:S56-S65.

4. Finkelstein JA, McMahon GT, Peters A, Cadigan R, Biddinger P, Simon SR. Teaching population health as a basic science at Harvard medical school. Acad Med. 2008;83(4):332-7.

5. McHardy K, Ariana P, Plugge E. Public health in practice: translating theory into action. Med Educ. 2011;45(11):1142.

6. Campos-Outcalt D. The integration of public health and prevention into all years of a medical school curriculum. Am J Prev Med. 2011;41(4):S306-S8. 7. Woodward A. Public health has no place in undergraduate medical education. J Public Health Med. 1994;16(4):389-92.

8. Shapiro J, Jones CS. The future of public health in England. BMJ. 2011;343:d4834.

9. Tyler VI, Hau AM, Buxton JJ, Elliott JL, Harvey CB, Hockin LJ, et al.
Canadian medical students' perceptions of public health education in the undergraduate medical curriculum. Acad Med. 2009;84(9):1307-12.

10. Bertoncello C, Buja A, Silenzi A, Specchia ML, Franchino G, Lazzari A, et al. Good governance competencies in public health to train public health physicians. Int J Public Health. 2015;60(6):737-49.

11. Davison H, Capewell S, Macnaughton J, Murray S, Hanlon P, McEwen J. Community-oriented medical education in Glasgow: developing a community diagnosis exercise. Med Educ. 1999;33(1):55-62.

12. DeBate RD, Petersen DJ, Wathington D, Wolfe-Quintero K. Our practice is our passion: development and delivery of a 21st-century doctor of public health program. Am J Public Health. 2015;105 Suppl 1:S27-33.

13. Association of Schools and Programs of Public Health (ASPPH). 2011. Undergraduate public health learning outcomes model. [Cited 20 May 2018]; Available from: https://www.aspph.org/teach-research/models/undergraduate-learning-outcomes/.

14. Andreatta PB, Hillard ML, Murphy MA, Gruppen LD, Mullan PB. Shortterm outcomes and long-term impact of a programme in medical education for medical students. Med Educ. 2009;43(3):260-7.

15. Baxley EG, Lawson L, Garrison HG, Walsh D, Lazorick S, Lake D, et al. The teachers of quality academy: a learning community approach to preparing faculty to teach health systems science. Acad Med. 2016;91(12):16551660.

16. Gwee MC. Globalization of problem-based learning (PBL): cross-cultural implications. Kaohsiung J Med Sci. 2008;24(3 Suppl):S14-22.

17. Koehn PH, Swick HM. Medical education for a changing world: moving beyond cultural competence into transnational competence. Acad Med. 2006;81(6):548-56.

18. Stewart T, Wubbena ZC. A systematic review of service-learning in medical education: 1998-2012. Teach Learn Med. 2015;27(2):115-22.

19. Gillam S, Maudsley G. Public health education for medical students: rising to the professional challenge. J Public Health (Oxf). 2010;32(1):125-31.

20. Rego PM, Dick ML. Teaching and learning population and preventive health: challenges for modern medical curricula. Med Educ. 2005;39(2):20213.

21. Campos AI. New professionalism, medical education and healthcare systems. Cien Saude Colet. 2011;16(6):2725-32.

22. Rolfe IE, Pearson SA. A scale to measure attitudes toward community medicine. Aust N Z J Public Health. 1996;20(4):433-5.

23. Johnston JM, Leung GM, Fielding R, Tin KY, Ho LM. The development and validation of a knowledge, attitude and behaviour questionnaire to assess undergraduate evidence-based practice teaching and learning. Med Educ. 2003;37(11):992-1000

24. Tavakol M, Sandars J. Quantitative and qualitative methods in medical education research: AMEE Guide No 90: Part I. Med Teach. 2014;36(9):74656.

25. Tavakol M, Sandars J. Quantitative and qualitative methods in medical education research: AMEE Guide No 90: Part I. Med Teach.2014;36(10):83848.

26. Ringsted C, Hodges B, Scherpbier A. 'The research compass': an introduction to research in medical education: AMEE Guide no. 56. Med Teach. 2011;33(9):695-709.

27. The School of Public Health. LKS Faculty of Medicine. the University of Hong Kong. 2017. Undergraduate public health curriculum for medical students. [Cited 20 May 2018]; Available from: http://sph.hku.hk/en/prospective-student/undergraduate-education.

28. Chwinner C. 2016. White paper 5-point vs. 6-point Likert scales: Infosurv. White paper. [Cited 20 May 2018]; Available from: http://www.infosurv.com/wp-content/uploads/2011/01/Likert_Scale_Debate.pdf.

29. Streiner DL, Norman GR, Fulton C. Health measurement scales: a practical guide to their development and use. Int J Rehabil Res. 1991;14(4):364.

30. Wright E, Kiely M, Johnston C, Smith A, Cull A, Selby P. Development and evaluation of an instrument to assess social difficulties in routine oncology practice. Qual Life Res. 2005;14(2):373-86.

31. Soleymanian A, Niknami S, Hajizadeh E, Shojaeizadeh D, Montazeri A. 
Development and validation of a health belief model based instrument for measuring factors influencing exercise behaviors to prevent osteoporosis in pre-menopausal women (HOPE). BMC Musculoskelet Disord.2014;15(1):61. 32. Joseph F. Hair. Multivariate data analysis. 7th ed. Hair JF, editor. Upper Saddle River, NJ: Prentice Hall; 2010.
33. McEvoy M, Williams M, Olds T. Development and psychometric testing of a trans-professional evidence-based practice profile questionnaire. Med Teach. 2010;32(9):E373-80.

34. Tavakol M. The reliability of assessment: the Bayesian Cronbach's alpha. Med Teach. 2017;39(5):561-3. 